\title{
Método educacional infantil na prevenção e combate à dengue, zika vírus e Chikungunya
}

\author{
Flávia Mesquita Soares ${ }^{1}$ \\ Ana Beatriz Clemente Gonçalves ${ }^{2}$ \\ Rafael de Oliveira Alvim ${ }^{3}$ \\ Carlos Alberto Mourão Júnior ${ }^{4}$ \\ Camila Maciel Oliveira ${ }^{5}$
}

Desde o século 19 o continente americano é palco de epidemias de dengue e, ainda nos dias de hoje os óbitos e impactos negativos nos setores de saúde, social e financeiro decorrentes do grande número de pessoas afetadas, incidem sobre diversos países do mundo. A situação complica-se ainda mais em 2016 quando a tríade de enfermidades transmitidas pelos mosquitos Aedes aegypti e Ae. albopictus começa a apresentar surtos: Dengue, Febre Chikungunya e Zika. É evidente a necessidade de se traçar programas que incentivem o combate aos vetores de forma eficaz. Toda a população deve ser convocada a participar de ações diárias de eliminação de focos de água parada, sendo essa a forma mais eficiente, até o momento, de controlar a reprodução do vetor. A fim de recrutar crianças no combate ao Aedes o Projeto Coraçõezinhos de Baependi realizou uma ação educativa em escolas das redes públicas e privadas, em zona urbana e rural, na cidade de Baependi - Minas Gerais em março de 2016. As atividades foram direcionadas aos escolares da educação infantil ao sexto ano do Ensino Fundamental. O público infantil, além de poder contribuir ativamente no processo, pode exercer papel fundamental na propagação de informações, especialmente em ambiente familiar.

Palavras-chave: dengue, chikungunya, zika vírus.

\section{Method in educational child prevent and combat dengue, zika virus and chikungunya}

Since the 19th century the American continent is a scene of dengue epidemics and, even today the deaths and negative impacts in health care, social and financial resulting from the large number of affected people, focus on several countries of the world. The situation is complicated even more in 2016 when the triad of diseases transmitted by mosquitoes Aedes aegypti and Ae. albopictus begins to present outbreaks Dengue, Chikungunya fever and Zika. The need for tracing programs which promote effectively combating vectors are evident. The entire population should be called to participate in daily actions of elimination of standing water spots, this being the most efficient way, so far, to control the reproduction of the vector. In order to recruit children to fight Aedes the Little Hearts Project of Baependi performed an educational action in public and private schools in urban and rural

\footnotetext{
${ }^{1}$ UNIPAC

${ }^{2}$ UNIPAC

${ }^{3} \mathrm{UFJF}$

${ }^{4}$ Médico, PhD, Professor Associado - UFJF

${ }^{5}$ Médica, PhD, Professora Adjunta - UFJF
} 
areas in the city of Baependi - Minas Gerais in March 2016. The activities were directed from the pre primary to the fifth grade of elementary school. The child audience, besides actively contribute to the process, can play a key role in the spread of information, especially in a family setting.

Keywords: dengue, chikungunya, zika vírus.

\section{INTRODUÇÃO}

Por serem vetores de vários arbovírus, os mosquitos Aedes (Stegomyia) são de grande importância médica. As espécies Ae. aegypti e Ae. albopictus são amplamente distribuídas por todo o mundo, especialmente em regiões tropicais e subtropicais, sendo que sua reprodução ocorre, preferencialmente, em locais de grande aglomeração humana. O Ae. albopictus é melhor adaptado ao ambiente silvestre e se alimenta de animais vertebrados, como humanos, cães, gatos e bois, ao passo que o Ae. aegypti apresenta filia por sangue humano. No Brasil, ainda não há comprovações de que o Ae. albopictus transmita o vírus da dengue (DENV), mas a sua relação com outras arboviroses necessita de maiores esclarecimentos (MARCONDES; XIMENES,2016).

Os hábitos populacionais estão diretamente relacionados à proliferação de Aedes aegypti. $\mathrm{O}$ armazenamento de água em recipientes e condições inadequadas, o descarte de embalagens na natureza, a falta e/ou ineficaz vistoria de focos de água parada, exemplificam alguns erros humanos que contribuem para a propagação do mosquito, sendo que, o lixo urbano constitui o principal local de reprodução. Além disso, eventos de grande porte, como a Copa do Mundo de 2014 e as Olimpíadas de 2016, são formas de inserção de diferentes vírus no país.

Dengue, febre Chikungunya e Zika vírus são afecções febris, sendo que cada uma apresenta sintomas predominantes em relação às demais. Por possuir diferentes sorotipos, a manifestação dos sintomas da dengue vai depender de inúmeros fatores como a genética viral, susceptibilidade do hospedeiro, reações cruzadas quando há infecções prévias, entre outras. Em geral, há predomínio de febre, dor retro orbitária, dores difusas no corpo e cefaleia. Deve-se ficar atento para os sintomas de alarme que sinalizam agravamento do quadro, como dores abdominais intensas e contínuas, vômitos persistentes, hipotensão postural e/ou lipotimia, hipotermia, diminuição da diurese, queda abrupta de plaquetas. Há testes específicos para dengue com os quais a suspeita pode ser confirmada. Atualmente, a dengue pode ser considerada uma pandemia uma vez que metade da população mundial está sujeita a infecção (NASCIMENTO et al.; 2015).

Revista Extensão em Foco, nº 13, Jan/ Jul (2017) p. 55 - 63. 
A febre Chinkungunya, como o próprio nome diz, refere-se a uma doença febril aguda podendo evoluir para uma condição reumática crônica incapacitante. No entanto, a tendência é que o quadro seja autolimitado. Até o presente momento não há tratamento disponível e o diagnóstico é confirmado por sorologia. Há relatos de possíveis transmissões do vírus CHIKV por meio da placenta de mãe para filho e por transfusões sanguíneas (MADARIAGA, TICONA, RESURRECION; 2016).

Já o Zika vírus é responsável por uma doença exantemática altamente pruriginosa associada à cefaleia, dores articulares, mialgia e febre baixa. Entretanto, apenas em abril de 2015 elucidou-se a etiologia desses quadros no Brasil. Além disso, no segundo semestre de 2015, o Zika vírus tornou-se emergência nacional ao ser correlacionado ao surto de microcefalia em filhos de mães infectadas durante o pré-natal (RIBEIRO, KITRON;2016).

O Projeto Coraçõezinhos de Baependi tem por finalidade a promoção de saúde juntamente com a prevenção de doenças infecciosas e cardiometabólicas. O projeto consiste em uma vertente do Projeto Corações de Baependi, primeiro estudo brasileiro em doenças cardiovasculares, com 2500 pacientes, posto próprio, equipe médica e fornecimento de exames complementares. O intuito de direcionar atividades aos estudantes de escolas públicas e privadas da cidade de Baependi-MG é tornar lúdico o processo de aprendizado, difundindo informações a partir de peças teatrais infantis, jogo de perguntas e respostas, cantigas. No ano de 2016, o Projeto Coraçõezinhos passou a abranger escolas da zona rural de Baependi. O Projeto Coraçõezinhos de Baependi possui extensão na cidade de Juiz de Fora - MG, onde atividades semelhantes são realizadas, e em Curitiba/PR onde treinamentos são realizados com professores do ensino fundamental a fim de possibilitar o desenvolvimento da prática pelos próprios educadores.

As ações consistem em interagir com os alunos da educação infantil ao sexto ano do Ensino Fundamental de forma a ensiná-los sobre um determinado tema, por meio de peça teatral e outras atividades que são preparadas previamente. Duas acadêmicas de Medicina da Universidade Presidente Antônio Carlos de Juiz de Fora (UNIPAC- JF/FAME-JF), devidamente orientadas por professores da UNIPAC-JF e da Universidade Federal de Juiz de Fora (UFJF), são as responsáveis pelo desenvolvimento da ação nas escolas.

As atividades do Projeto Coraçõezinhos de Baependi são mensais e as datas das apresentações são marcadas antecipadamente junto à secretaria das instituições. Vários temas já foram abordados, como respeito ao idoso, economia de energia elétrica, saúde óssea e bucal, prevenção de doenças cardiometabólicas e alimentação saudável.

Revista Extensão em Foco, nº 13, Jan/ Jul (2017) p. 55 - 63. 
Com o elevado número de casos de infecções virais por vírus da dengue, Zika e Chikungunya, as instituições educacionais devem dar maior enfoque à prevenção e ao reconhecimento de sinais e sintomas de alarme, a fim de propiciar o combate ao mosquito e, consequentemente, menor número de pessoas acometidas e com complicações graves. Desse modo, o Projeto Coraçõezinhos de Baependi propôs trabalhar com o tema em escolas das zonas urbana e rural da cidade de Baependi.

\section{MATERIAIS E MÉTODOS:}

Realizou-se nos dias 29 e 30 de março de 2016, na cidade de Baependi, Minas Gerais, ações educativas direcionadas a alunos entre quatro a dez anos em escolas da rede pública e privada. O intuito é promover maior conhecimento sobre os sintomas, ciclo reprodutivo dos vírus, formas de eliminação dos focos de reprodução dos vetores, além de sanar dúvidas de alunos, professores e funcionários. É importante salientar que houve orientação para que a população reconheça os sinais de alarme da dengue a fim de possibilitar atendimento médico precoce.

Duas acadêmicas de Medicina da Universidade Presidente Antônio Carlos de Juiz de Fora, previamente treinadas e orientadas para realização do projeto extensionista, são as responsáveis pela confecção dos fantoches utilizados, realização da peça teatral e aplicação das atividades.

A ação consiste em ofertar conhecimento a crianças desde a educação infantil ao sexto ano do Ensino Fundamental utilizando teatro infantil com fantoches, paródia de música infantil, jogo de perguntas e respostas e uma atividade didática complementar para o aluno levar para a casa.

Para o teatro utiliza-se uma peça infantil que aborde o tema de forma simples e clara, com enfoque nos principais pontos referentes à prevenção, sintomatologia e medidas a serem adotadas para controle da proliferação do mosquito. A peça utilizada é de autoria própria e intitulada: "Senhor Aedes, aqui não". Trata-se de um teatro interativo, onde os alunos são convidados a participar durante a peça. A história gira em torno de um mosquito fêmea de Aedes aegypti que encontra um recipiente com água parada. Ali ele decide ovipositar e desafia as crianças presentes ao dizer que ninguém o vai impedir e que as pessoas possuem pouco conhecimento sobre ele e sobre as doenças que transmite. Dessa forma, o mosquito direciona o debate e, com o auxílio de uma das graduandas responsáveis pelo projeto, alguns alunos são Revista Extensão em Foco, nº 13, Jan/ Jul (2017) p. 55 - 63. 
chamados à frente para explicar aos demais sobre os questionamentos lançados pelo mosquito. Os alunos que se dispõe a ir à frente da turma respondem a sua maneira e, junto com a aplicadora, proferem frases simples e explicativas para que todos os presentes repitam.

Para a encenação, utilizou-se uma cortina de teatro, um recipiente com água em seu interior e um mosquito confeccionado com garrafa pet e EVA. Uma das aplicadoras do projeto articula o mosquito por detrás da cortina e a outra, a frente da cortina, dialoga com o mosquito e a turma.

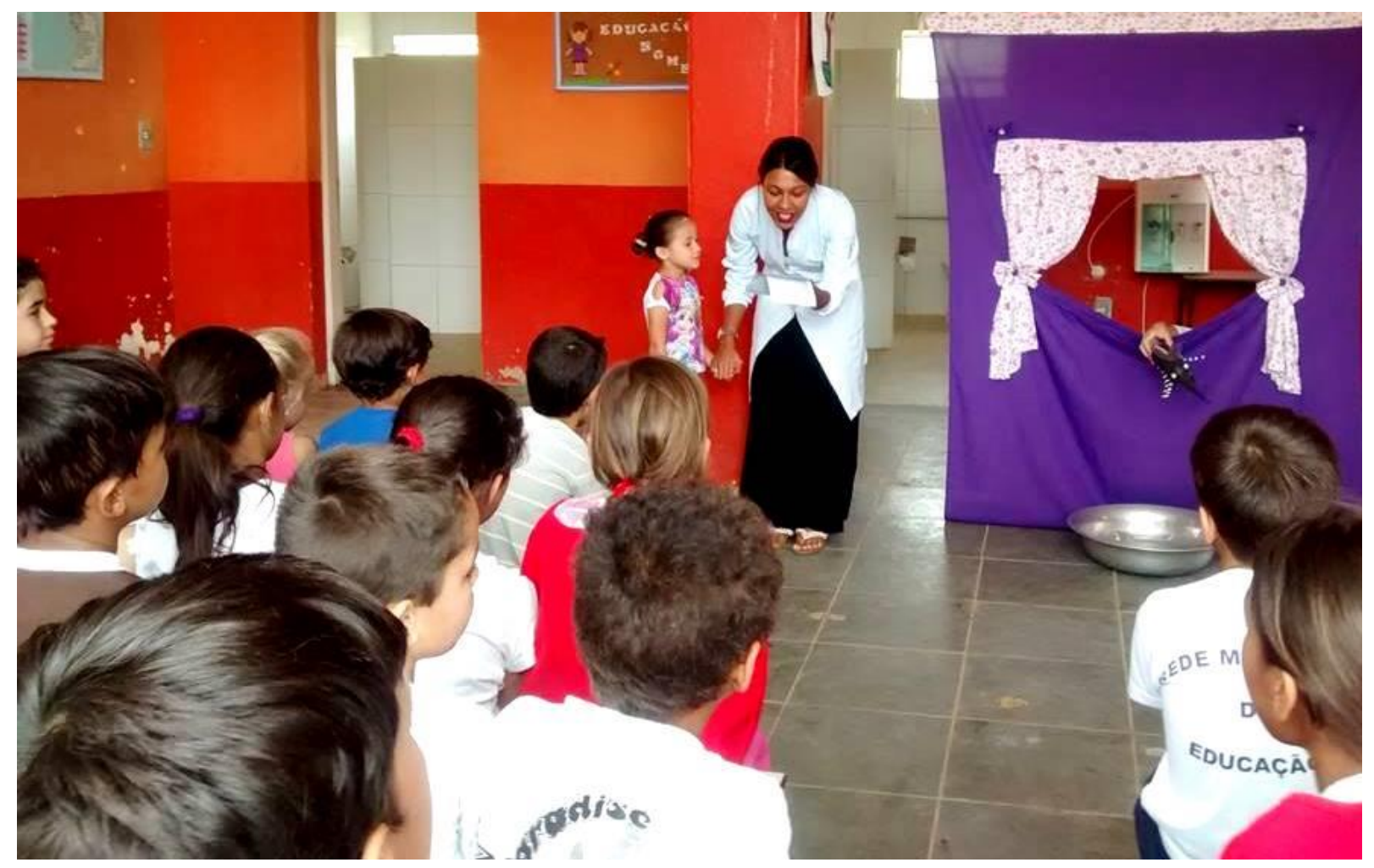

Ilustração 1 - Peça teatral em escola da zona rural

Fonte: Própria, 2016.

Os objetos utilizados para a execução da peça teatral são simples e de fácil confecção. Fotos dos materiais utilizados, das atividades, bem como o registro do número de crianças presentes em cada escola são disponibilizados em uma página do projeto em rede social. Lá é possível ter acesso ao registro de todas as ações já efetuadas em Baependi.

Com o intuito de proporcionar um momento de descontração com os estudantes presentes, a paródia infantil "Atirei o pau na dengue", retirada do blog Guisado da Leitura (2016), foi ensinada e cantada por todos. A mesma foi escrita no quadro negro quando este estava presente na sala de apresentações, de modo que as crianças poderiam ler e cantar. $\mathrm{O}$

Revista Extensão em Foco, nº 13, Jan/ Jul (2017) p. 55 - 63. 
quadro também foi útil para desenhar lugares em que, comumente, encontra-se água parada, exemplificando aos alunos locais simples onde o mosquito pode estar a se reproduzir.

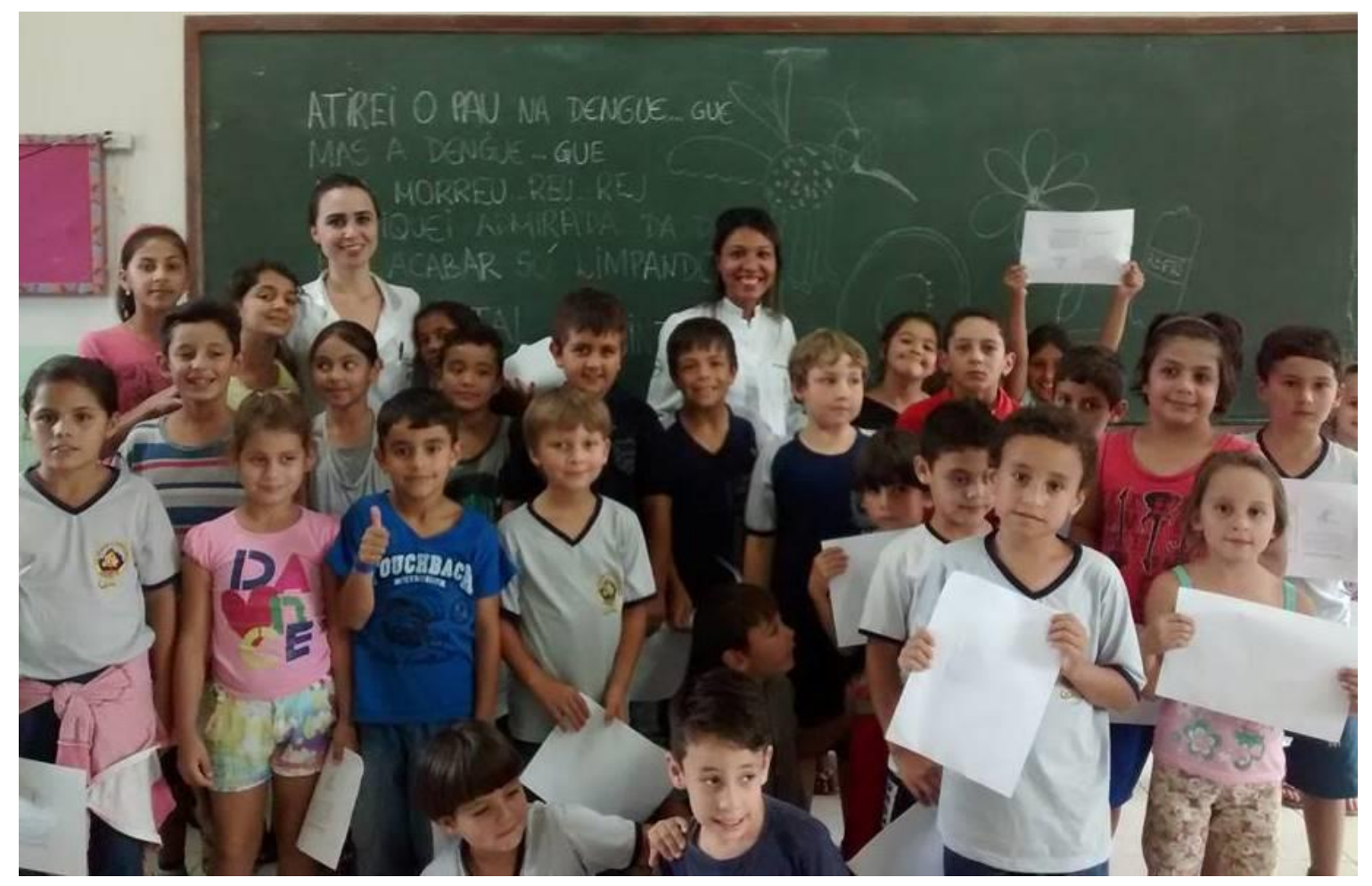

Imagem 2 - Crianças exibindo atividades didáticas e, ao fundo, a cantiga escrita no quadro negro. Fonte: Própria, 2016.

Logo após, realizou-se um quiz onde as perguntas previamente formuladas pelas graduandas eram respondidas por duas crianças chamadas à frente da turma. A cada nova pergunta, duas crianças diferentes eram convidadas a responder e os demais alunos eram os responsáveis por dizer se as respostas estavam corretas ou não. Algumas questões que foram utilizadas no quiz são as seguintes: "A dengue é uma doença contagiosa?"; "É verdade que manter o quintal limpo sem água parada e usar repelentes corporais pode evitar que a pessoa fique doente?"; "Qual é o nome da alteração que pode ser causada nos filhos de grávidas com zika vírus?"; "É verdade que quando a pessoa está com chikungunya ela pode ter dor nas articulações?".

Ao término do jogo de perguntas e respostas, foram distribuídas duas atividades didáticas, sendo um caça-palavras e um pequeno texto descritivo sobre características do mosquito transmissor da dengue. As crianças menores que não conseguem ler foram instruídas a colorir as imagens e a mostrar o texto aos familiares. 


\section{COMO É O MOSQUITO QUE TRANSMITE A DENGUE?}

É um mosquito rajado, geralmente escuro, com manchas brancas no corpo. Sua maior caracteristica é a presença de um desenho prateado na parte dorsal do tórax. Ele pica principalmente durante 0 dia. A fêmea se alimenta de sangue, pois é necessário para o amadurecimento dos ovos.

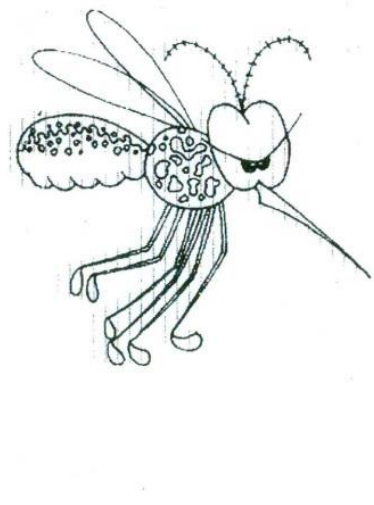

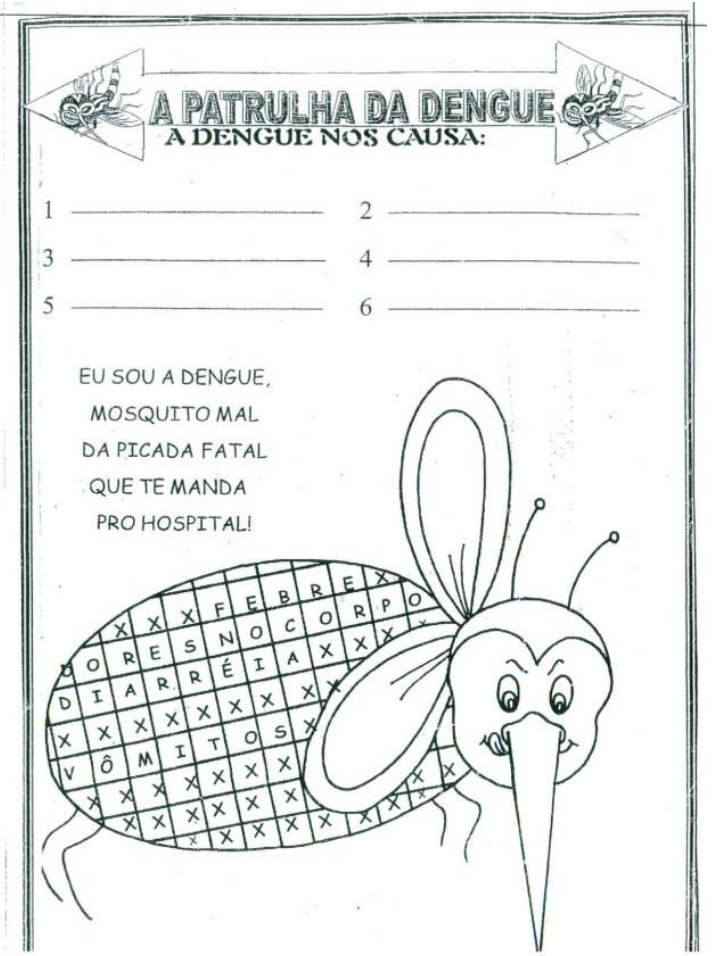

Ilustração 3 - Atividades didáticas oferecidas aos alunos

Fonte: www.ensinar-aprender.com.br

Panfletos informativos sobre a prevenção e o combate à dengue foram ofertados aos educadores e funcionários das instituições. Os panfletos utilizados são distribuídos pelo Ministério da Saúde e possuem uma tabela de ações a se realizar no dia-a-dia a fim de se eliminar focos de água de parada.

\section{RESULTADOS E DISCUSSÃO:}

Por ser um assunto intensamente discutido nos dias atuais nas escolas, em casa, via emissoras de televisão e rádio, percebeu-se que as crianças estão bem informadas, no entanto com muitas dúvidas. Além disso, por ser um assunto com o qual elas estão mais familiarizadas, houve grande interesse em participar da peça, do jogo de perguntas e respostas, além de contribuir com histórias de conhecidos acometidos por alguma das doenças.

Pôde-se perceber que os alunos tinham maior conhecimento sobre a dengue e, o zika vírus foi o responsável pela maior parte das dúvidas tanto de estudantes quanto de funcionários das escolas. Isso se deve ao fato de o zika vírus ser um tema de discussão mais recente na sociedade quando comparado à dengue.

Revista Extensão em Foco, nº 13, Jan/ Jul (2017) p. 55 - 63. 
O Projeto Coraçõezinhos de Baependi, com suas experiências prévias, apostou em uma peça teatral mais dinâmica e com maior participação dos ouvintes. Isso porque, o fato de um amigo estar à frente da turma respondendo a uma questão e a possibilidade de também participar mantém as crianças focadas no assunto discutido, evitando dispersões. Além disso, quando se tem uma das aplicadoras do projeto à frente da cortina, ela pode perceber mais facilmente o grau de atenção das crianças e, se necessário, estimular o retorno do foco à peça.

Os alunos foram extremamente participativos e colaborativos para o êxito de todas as atividades. Acredita-se que estes foram bastante estimulados a difundir seus novos conhecimentos e colaborar na conscientização das pessoas próximas e na exclusão dos focos de água parada. Dessa forma, contribui-se para a diminuição dos vetores e consequente supressão dos casos de doenças, hospitalizações e óbitos pelas respectivas moléstias.

Baseados em experiências prévias, preferiu-se não realizar as atividades com alunos de classes mais avançadas. Isso porque, em uma das apresentações do projeto abrangendo o sexto ano do ensino fundamental, percebeu-se que essa classe se manteve mais dispersa e que houve menor aceitação à peça devido a abordagem mais infantil. Para se englobar alunos de faixas etárias superiores propõe-se uma didática menos lúdica, com discussões do tema e linguagem voltadas ao público adolescente.

\section{CONCLUSÕES:}

Atualmente, o controle dos mosquitos Stegomyia é a principal forma de controle de arboviroses como dengue, chikungunyia e zika. Isso porque, alternativas como a inserção de machos estéreis e bactérias Wolbachia associadas a inseticidas ainda carecem de maiores investigações e a vacinação existente contempla apenas o DENV.

É importante frisar que, além de propagar informações, um dos intuitos da ação educativa é despertar interesse nos alunos para que estes contribuam para eliminar de focos de reprodução do Aedes no dia-a-dia. As crianças devem ser cada vez mais instigadas a participar do processo de erradicação dos focos de água parada. Isso porque possuem disposição e podem fazê-lo brincando. Ao explorar diferentes locais no quintal ou em casa durante seus momentos de lazer, muitos focos de água parada podem ser encontrados e, se orientada, a criança o irá descartar.

Revista Extensão em Foco, no 13, Jan/ Jul (2017) p. 55 - 63. 
Devemos ter em mente que, como se trata da melhor forma de controle dos mosquitos transmissores, toda a ajuda em prol de eliminá-lo é essencial. As crianças também podem ser aliadas no combate à dengue, Zika vírus e Chikungunya.

\section{REFERÊNCIAS:}

MADARIAGA, M; TICONA, E; RESURRECION, C. Chikungunya: bending over the Americas and the rest of the world. The Brazilian Journal of Infectious Diseases, vol. 20, n.1, p. 91-98, 2016.

MARCONDES, C.B; XIMENES, M.F.F.M. Zika vírus in Brazil and the danger of infestation by Aedes (Stegomyia) mosquitoes. Revista da Sociedade Brasileira de Medicina Tropical, Uberaba, vol. 49, n. 1, p. 4-10, jan./fev. 2016.

NASCIMENTO, L.B. et al. Caracterização dos casos suspeitos de dengue internados na capital do estado de Goiás em 2013: período de grande epidemia. Epidemiologia e Serviços de Saúde, Brasília, vol. 24, n. 3, p. 475-484, jul/set. 2015.

RIBEIRO, G.S; KITRON, U. Zika vírus pandemic: a human and public health crisis. Revista da Sociedade Brasileira de Medicina Tropical, vol. 49, n.1, p. 1-3, jan/fev. 2016. 